\title{
Cyclic esotropia and the treatment of over-elevation in adduction and V-pattern
}

\author{
J W R Pott, D Godts, D B Kerkhof, J T H N de Faber
}

Br J Ophthalmol 2004;88:66-68

\begin{abstract}
Aim: To describe the development and treatment of V-pattern and bilateral over-elevation in adduction in patients with cyclic esotropia.

Methods: Three patients with cyclic esotropia are described in retrospect. All patients underwent bilateral medial recession, while one patient additionally had a weakening procedure of both inferior oblique muscles.

Results: All patients developed a V-pattern and bilateral over-elevation in adduction. After strabismus surgery, normal eye alignment with some signs of binocularity was reached in all three patients. Moreover, the over-elevation in adduction and V-pattern completely resolved.

Conclusions: $V$-pattern and bilateral over-elevation in adduction was seen in all patients with cyclic esotropia in the stage that fusion was disrupted. Possible explanations for the origin of these patterns are discussed. Strabismus surgery aimed to correct the horizontal esotropic angle restored fusion and eliminated the vertical incommitancies in lateral gaze, and the V-pattern.
\end{abstract}

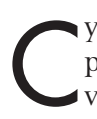
clic esotropia is a regularly recurring esotropia, usually present in an alternate day pattern. It is not related to visual acuity, accommodation, fatigue, or non-fusion. The aetiology of cyclic esotropia remains unknown, although a relation with the biological clock mechanism is suspected..$^{1-4}$ Cyclic esotropia is a rare phenomenon. It has been calculated that an ophthalmologist, even one with an interest in strabismus, would expect to practise for 14 years for each cyclic esotropia patient seen. ${ }^{1}$

In 1974, Helveston mentioned the V-pattern as one of the characteristics of cyclic esotropia. ${ }^{1}$ In that same year, Hiles described a patient who had developed a V-pattern with overelevation in adduction 4 months after the onset of cyclic esotropia. This patient was treated with surgery on both medial rectus muscles and a weakening procedure on the inferior oblique muscles. ${ }^{2}$

Recently one of the present authors treated a patient with cyclic esotropia, accompanied by a V-pattern with bilateral over-elevation in adduction (patient 1). After performing a bilateral medial recession, fusion was restored and, interestingly, the V-pattern and over-elevation in adduction also resolved. This observation implicates a role for loss of fusion in the development of V-pattern and over-elevation in adduction and a simple treatment for these incommitancies in selected cases. To further examine this phenomenon, more cases of cyclic esotropia have been traced retrospectively.

\section{PATIENTS AND METHODS}

All cases of cyclic esotropia known to the authors in their own practice have been collected retrospectively. Altogether, five patients were traced. The data of two patients were excluded because they presented with a more complicated medical history. Their clinical history did not serve the purpose of this study. One of these two patients had developed a torticollis because of a V-pattern esotropia. Only after some years had an actual cyclic pattern of esotropia developed. It was not recorded whether the torticollis also varied in a cyclic pattern. The other excluded patient had been treated for esotropia with bilateral medial recession and a bilateral weakening procedure of the inferior oblique muscles; 3 years postoperatively, a cyclic esotropia developed. The three other cases had a more clearcut history of cyclic esotropia and will be described in more detail.

\section{RESULTS}

\section{Patient 1}

A 2 year old boy visited the outpatient department because his parents had noticed squinting. At the first visit an orthophoria was noted with normal motility and positive stereoscopic vision with the Lang test. Further examination did not reveal any abnormalities. Refraction in cycloplegia was +2.0 for both eyes. After 1 month, the patient was seen again. The mother had noticed a clear alternate day pattern of squinting, which was confirmed by a home video. At the examination the patient had an esotropia of the left eye of $15^{\circ}$ with a clear V-pattern and bilateral over-elevation in adduction. The next day the alignment was straight again, with a small V-pattern and small bilateral over-elevation in adduction. After 5 months the parents were convinced of the benefit of surgery. In that period the cyclic esotropia of the left eye became constant and the bilateral over-elevation in adduction and V-pattern persisted. A $5 \mathrm{~mm}$ bilateral medial recession (BMR) was performed without surgery on the inferior oblique muscles. The postoperative alignment was orthophoria with positive stereoscopic vision (Titmus test) and good fusional potential. Follow up examination 4 months postoperatively showed that the cyclic esotropia and the bilateral over-elevation and V-pattern had resolved.

\section{Patient 2}

This 3 year old boy had an almost identical history, with a sudden onset of intermittent esotropia that became cyclic (48 hour cycle) after 6 months. On a squinting day he had an alternating esotropia of the right eye of $15^{\circ}$ for both fixation at near and at distance, with bilateral over-elevation in adduction and a V-pattern. Refraction in cycloplegia was +1.75 for both eyes. Further ophthalmological examination was without abnormalities. On a "straight" day he had a small esophoria, no motility abnormalities, and positive stereoscopic function with both Lang and Titmus tests. After 1 year, without resolution of the cyclic esotropia, the decision to perform surgery was made. A BMR was performed, again without a weakening procedure of the inferior oblique muscles. Postoperatively, the eyes were orthophoric, the cyclic pattern had disappeared. Moreover, the V-pattern had disappeared, although a small bilateral over-elevation in adduction was still present. After 
22 months the over-elevation in adduction had also completely resolved. The patient had positive stereoscopic vision (40 seconds of arc).

\section{Patient 3}

This 3 year old girl presented with an acute onset of squint. The parents had noticed some intermittent squinting in the year before. On examination, an esotropia of the left eye of $20^{\circ}$ was found for both fixation at near and at distance. Refraction in cycloplegia was $+1.50 \mathrm{D}$ for both eyes. The records did not mention any further motility abnormalities. After some weeks, a clear cyclic esotropia of the left eye was recorded by the parents with a 48 hour cycle. After 2 months she developed bilateral over-elevation in adduction. There was no mention of a V-pattern in the records. The decision for strabismus surgery was soon made. A BMR with a weakening procedure of both inferior oblique muscles was performed. Postoperatively the eyes were straight with positive stereoscopic vision (Titmus test: 100 seconds of arc) and normal fusion capacity. The cyclic pattern had resolved, as did the bilateral over-elevation in adduction. Follow up has been for 9 years.

\section{DISCUSSION}

We describe three patients with cyclic esotropia, who developed a V-pattern and/or bilateral over-elevation in adduction during the course of their disease. Two of these patients were successfully treated by a bilateral medial recession only. The vertical incommitancy completely resolved without the necessity of a weakening procedure of the inferior oblique muscles.

Many theories exist on the origin of V-patterns and bilateral over-elevation in adduction. The over-elevation in adduction is often described as an overaction of the inferior oblique muscle, as this muscle is an elevator in adduction. Also, over-elevation in adduction can be treated by weakening procedures of the inferior oblique muscle. ${ }^{5}$ Furthermore, a bilateral superior oblique muscle palsy is characterised by over-elevation in adduction and V-pattern. ${ }^{6}$ However, it has never been validated that the inferior oblique muscles are indeed overacting in V-patterns and bilateral over-elevation in adduction. ${ }^{7}$

Orbital factors have been mentioned as a cause of overelevation in adduction and V-patterns. For example, patients with craniosynostosis have an excyclotorsion of their orbits causing a vertical incommitance. ${ }^{8}$ In the first half of the 20th century abnormal muscle insertions were observed in some patients with a V-pattern. ' More recently, heterotopia of muscle pulleys has been described as one of the causes of over-elevation in adduction and V-patterns. ${ }^{10}$ However, as orbital factors are more or less static in character, this is unlikely to be the cause of the existence of V-pattern and bilateral over-elevation in adduction in patients with cyclic esotropia.

In 1994 Guyton and Weingarten postulated that loss of fusion not only results in loss of horizontal fusion but can also induce a "sensory excyclotorsion."11 The existence of excyclotorsion in some patients with V-pattern has already been reported in 1964 by Piper $^{12}$ and in 1966 by Weiss. ${ }^{13}$ Because of the excyclorotation of the globe, the medial rectus muscles will act not only as an adductor but also as an elevator. The vertical rectus muscles are also shifted in the orbit thereby causing the V-pattern. As a demonstration of the sensory excyclotorsion theory, Miller and Guyton described a series of patients who had been surgically overcorrected for an intermittent exotropia. Either an A or a V-pattern had developed in $43 \%$ of the patients with a secondary esotropia while they exhibited a predominance for the V-patterns. ${ }^{14}$ Moreover, animal studies in cats have shown that rearing in the dark or patching of one eye for a certain period leads to cyclotorsion with vertical incommitancies in adduction. ${ }^{15} 16$ Liesch and Simonsz have repeated this patching experiment in normal human volunteers and noted that 11 out of 18 individuals developed a small but significant over-elevation in adduction of the patched eye and two developed overdepression in adduction of the patched eye. ${ }^{17}$

In $1916 \mathrm{Ohm}$ postulated that pattern strabismus combined with over-elevation or overdepression in adduction may be due to abnormal vestibular innervation. Brodsky and Donahue have further elaborated on this theory in a recent paper. They suggested that one of the oblique muscle functions in lateral eyed animals is to control eye movements during body movements or in reaction to directional luminance shifts in the pitch plane of the body. In their theory, these primitive ocular motor reflexes become manifest in humans when fusion is lost. This is recognised by the central vestibular system as a forward pitch, leading to an increased upward tonus to the extraocular muscles and a manifest primary oblique muscle overaction with a Vpattern. ${ }^{18}$

In conclusion, bilateral over-elevation in adduction and Vpattern are common in cyclic esotropia. This phenomenon seems to develop during the course of the disease, and is probably caused by loss of fusion. The relation to excyclotorsion could not be confirmed in the present retrospective study, as fundus torsion was not documented systematically by funduscopy or photography. Our results indicate that horizontal surgery only, with restoration of fusion, can abolish the vertical incommitance completely. The current literature gives no answer to the question of whether the same holds for other forms of strabismus with V-pattern and bilateral over-elevation in adduction when there is good fusional potential.

\section{Authors' affiliations \\ J W R Pott, D B Kerkhof, Department of Ophthalmology, University Hospital Groningen, Netherlands \\ D Godts, Department of Ophthalmology, University Hospital Antwerp, Belgium \\ J T H N de Faber, The Eye Hospital Rotterdam, Netherlands}

Correspondence to: Dr Jan W R Pott, Department of Ophthalmology, University Hospital Groningen, Netherlands; j.w.r.pot!@ohk.azg.nl

Accepted for publication 14 April 2003

Previously presented at the 9th meeting of the International Strabismological Association (ISA) in Sydney, Australia, April 2002.

\section{REFERENCES}

1 Helveston EM. Cyclic strabismus. Am Orthoptic J 1973;23:48-51.

2 Hiles DA. Cyclic V esotropia. J Pediatr Ophthalmol 1973;10:147-51.

3 Hess JE. Cyclic esotropia-a case history. Am Orthoptic J 1974;24:83-5.

4 Stärk N Walther C. Cyclische Esotropie bei einem Erwachsenen. Klin Monatsbl Augenheilkd 1984:184:553-7.

5 Jampolsky A. Oblique muscle surgery of the A-V patterns. J Pediatr Ophthalmol Strabismus 1965;2:31-6.

6 von Noorden GK, Murray E, Wong SY. Superior oblique paralysis. A review of 270 cases. Arch Ophthalmol 1986:104:1771-6.

7 Demer JL. Clarity of words and thoughts about strabismus. Am J Ophthalmol 2001; 132:757-9

8 Cheng H, Burdon MA, Shun-Shin GA, et al. Dissociated eye movements in craniosynostosis: a hypothesis revived. Br J Ophthalmol 1993;77:563-8.

9 Cords R. Strabismus convergens surso-adductorius. Ber Dtsch Ophthalmol Ges 1922;43:158-61

10 Clark RA, Miller JM, Rosenbaum AL, et al. Heterotopic muscle pulleys or oblique muscle dysfunction? J AAPOS 1998;2:17-25.

11 Guyton DL, Weingarten PE. Sensory torsion as the cause of primary oblique muscle overaction/underaction and A- and V-pattern strabismus. Binocul Vis Eye Muscle Surg Q 1994;9:209-36.

12 Piper HF. Verlagerte Muskelansätze als eine Ursache des Schrägschielens (und ihre operative Korrectur). In: Sitzungsbericht 109 Versammlung Rheinland Westfalen Augenärzte 1964:86. 
13 Weiss JB. Ectopies et pseudoectopies maculaires par rotation. Bull Mem Soc Fr Ophtalmol 1966;79:329-49.

14 Miller MM, Guyton DL. Loss of fusion and the development of A or V-patterns. J Pediatr Ophthalmol Strabismus 1994;31:220-4.

15 Cynader M. Interocular alignment following visual deprivation in the cat. Invest Ophthalmol Vis Sci 1979;18:726-41.
16 Viirre E, Cadera W Vilis T. The pattern of changes produced in the saccadic system and vestibulocular reflex by visually patchingoneeye. JNeurophysio/ 1987;57:92-103.

17 Liesch A, Simonsz HJ. Up- and downshoot in adduction after monocular patching in normal volunteers. Strabismus 1993;1:25-36.

18 Brodsky MC, Donahue SP. Primary oblique muscle overaction. The brain throws a wild pitch. Arch Ophthalmol 2001;119:1307-14.

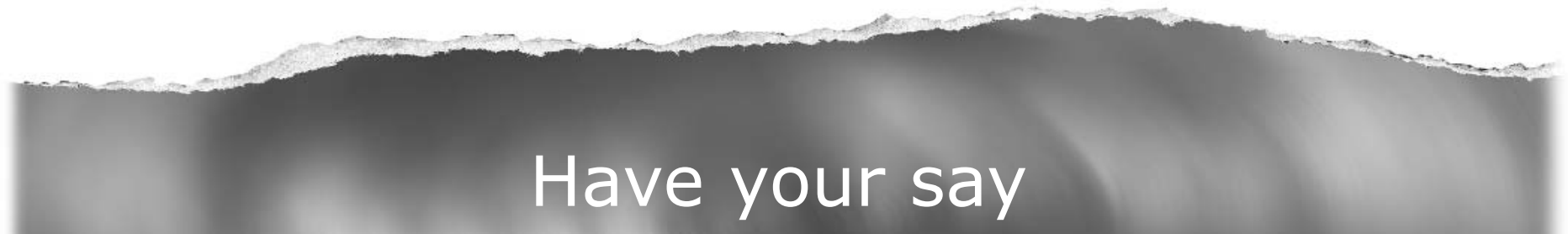

\section{eLetters}

If you wish to comment on any article published in the British Journal of Ophthalmology you can send an eletter using the eletters link at the beginning of each article. Your response will be posted on British Journal of Ophthalmology online within a few days of receipt (subject to editorial screening).

www.bjophthalmol.com 